\title{
Fixation and Permeabilization Approaches for Scanning Electrochemical Microscopy of Living Cells
}

\author{
Alexandra Bondarenko, ${ }^{* \dagger}$ Tzu-En Lin, $^{\dagger}$ Petar Stupar, $^{\S}$ Andreas Lesch, ${ }^{\dagger}$ Fernando Cortés-Salazar, $^{\dagger}$ \\ Hubert H. Girault, ${ }^{\dagger}$ and Horst Pick*, ${ }^{*}$ \\ ${ }^{\dagger}$ Laboratoire d’Electrochimie Physique et Analytique, EPFL Valais Wallis, École Polytechnique Fédérale de Lausanne, CH-1951 Sion, \\ Switzerland \\ ${ }^{\ddagger}$ Laboratory of Physical Chemistry of Polymers and Membranes, École Polytechnique Fédérale de Lausanne, CH-1015 Lausanne, \\ Switzerland \\ ${ }^{\S}$ Laboratory of the Physics of Living Matter, École Polytechnique Fédérale de Lausanne, CH-1015 Lausanne, Switzerland
}

Supporting Information

ABSTRACT: Scanning electrochemical microscopy (SECM) has been widely used for the electrochemical imaging of dynamic topographical and metabolic changes in alive adherent mammalian cells. However, extracting intracellular information by SECM is challenging, since it requires redox species to travel in and out the lipid cell membrane. Herein, we present cell fixation and permeabilization approaches as an alternative tool for visualizing cell properties by SECM. With this aim, adherent cells were analyzed in the SECM feedback mode in three different conditions: (i) alive; (ii) fixed, and (iii) fixed and permeabilized. The fixation was carried out with formaldehyde and does not damage lipid membranes. Therefore, this strategy can be used for the SECM

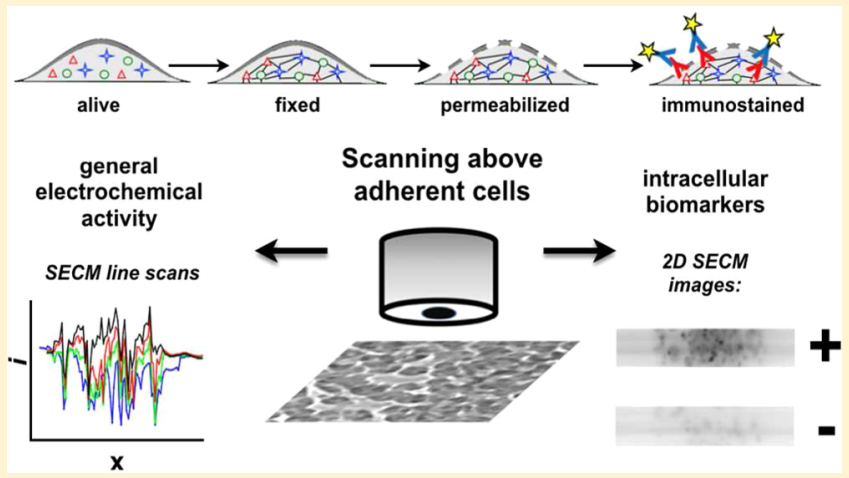
investigation of cell topography or the passive transport of the redox mediator into the cells. Additional permeabilization of the cell membrane after fixation enables the analysis of the intracellular content through the coupling of SECM with immunoassay strategies for the detection of specific biomarkers. The latter was successfully applied as an easy and fast screening approach to detect the expression of the melanoma-associated marker tyrosinase in adherent melanoma cell lines corresponding to different cancer progression stages using the SECM substrate generation-tip collection mode. The present approach is simple, fast, and reliable and can open new ways to analyze cell cultures with electrochemically based scanning probe techniques.

S canning electrochemical microscopy (SECM) is a surface reactivity characterization technique based on a faradaic current recorded at a microelectrode positioned or scanned in close proximity to a substrate. ${ }^{1-4}$ Thanks to its high spatial resolution and versatility, SECM has been used for the electrochemical imaging and intracellular investigation of different living cell types, including mammalian cells. ${ }^{5-10}$ Typically, SECM experiments are performed on single cells adherently grown on glass or plastic surfaces; however, they can also be applied to highly dense cell cultures that mimic more realistic conditions experienced in real tissues. Thus, SECM investigations of cell layers, ${ }^{11,12}$ patterns, ${ }^{13-15}$ and single embryos $^{16-20}$ have been reported as well. Frequently, SECM studies of cells are based on the monitoring of their respiratory activity $^{16-18,21,22}$ and production of specific signaling compounds, such as reactive oxygen species (ROS), ${ }^{23-25}$ nitric oxide (NO), ${ }^{26}$ and adrenaline, ${ }^{27}$ which can be detected in a label-free and noninvasive way in the extracellular space of cell cultures. In contrast, measuring the intracellular enzymatic activity requires special redox mediators that can penetrate into the cells. For instance, it was reported that ferrocenemethanol
$(\mathrm{FcMeOH})$ can pass through the lipid bilayer ${ }^{28}$ and evoke glutathione expression in alive cervical cancer cells (HeLa), which further provides the regeneration of electrochemically oxidized FcMeOH. ${ }^{29-31}$ Similarly, the cell membrane was shown to be permeable for the menadione/menadiol redox couple, which was employed for distinguishing metastatic and nonmetastatic breast cancer cell lines. ${ }^{32-35}$ While hydrophobic redox mediators can penetrate into the intracellular space, the lipid membrane stays generally impermeable for hydrophilic compounds. ${ }^{36}$ The cell surface behaves like a pure insulator, and the distance-dependent hindered diffusion current over the cells can be correlated with cell topography. ${ }^{37,38}$ Alternatively, alive cell membrane perforation with nonionic detergents allows the investigation of the intracellular enzyme activity even with hydrophilic redox mediators. ${ }^{39}$ However, such an approach results in the release of the intracellular content.

Received: June 21, 2016

Accepted: November 2, 2016

Published: November 2, 2016 
Furthermore, SECM investigation of cell membrane permeability can be important to study cytotoxicity, e.g., provoked by heavy metals. ${ }^{40-43}$ Additionally, specific antigens at adherent cells can be labeled with enzymes. ${ }^{44,45}$ However, the latter was employed only for surface antigens but not for the detection of intracellular markers.

In spite of many successful applications, the interpretation of experimental SECM data obtained from living cell studies is still cumbersome due to (i) cell-to-cell variability in terms of metabolic activity, (ii) possible dynamic morphological changes of cells, (iii) experimental time restrictions (e.g., experimental buffer solutions and redox mediators can be toxic for cells during long-term experiments), and (iv) perturbation of the cell metabolic response by the species generated or consumed at the SECM probe. One promising strategy to overcome these limitations could be the implementation fixation and permeabilization approaches.

Fixation is a process commonly used in biology that eliminates the cell biological activity and dynamic variability but preserves the cellular ultrastructure as well as proteins, carbohydrates, and other bioactive moieties in their original spatial organization within the cells. Fixatives which cross-link proteins (e.g., formaldehyde and glutaraldehyde) do not permeabilize the cell membrane and have been used previously in combination with some scanning probe techniques, e.g., in atomic force microscopy (AFM) to avoid topographical cell changes ${ }^{46-48}$ and in scanning ion-conductive microscopy (SICM) for the volume quantification of epithelial kidney cells. ${ }^{4950}$ Additionally, the subsequent permeabilization of fixed cells with organic solvents or surfactants to dissolve the lipids from the cell membrane makes the intracellular space accessible for various compounds, ${ }^{51}$ such as redox mediators or antibodies (Abs).

Herein, we have introduced the concept of cells fixation and permeabilization for SECM investigation of living cells in order to identify the most reliable and practical cell status in combination with a redox mediator (i.e., hydrophilic or hydrophobic) to access the relevant biological information and, thus, to extend the scope of SECM applications for cell analytics. Since it was not yet reported in the literature before, a detailed analysis of each cell state has been performed, thus, the influence of the probe translation speed and the cell density on the SECM signal for each case of cell status.

Finally, since the fixation/permeabilization approach offered the possibility to access the intracellular space electrochemically, it was successfully combined with the immunostaining approach in order to map electrochemically the intracellular melanoma biomarker tyrosinase $(\mathrm{TyR}) .^{52}$

\section{MATERIALS AND METHODS}

Details about the used chemicals and cell culturing procedures can be found in Supporting Information, section SI-I.

Sample Preparation. For SECM experiments cells were grown within a specifically prepared polyimide (PI) mask for cell patterning (Figure 1a, details in Supporting Information, section SI-II). Samples were prepared containing either the same melanoma cell line (i.e., WM-115) grown at different cell densities or different melanoma cell lines (i.e., Sbcl2, WM-115, and WM-239) as well as the different cell types (i.e., WM-115, HeLa, and MCF-7) grown at similar density. To obtain three cell lines with different densities, WM-115 cells were seeded into each chamber of the mask. The highest concentration (C1 $=5 \times 10^{5}$ cells $/ \mathrm{mL}$ ) was three times diluted to obtain the a
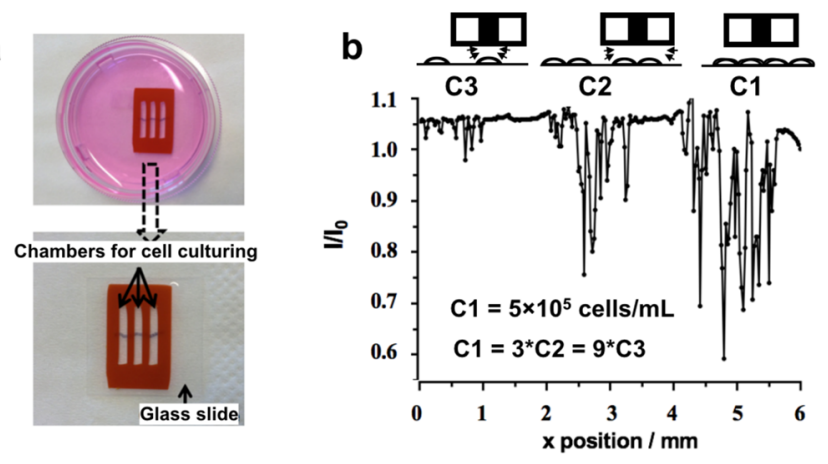

C

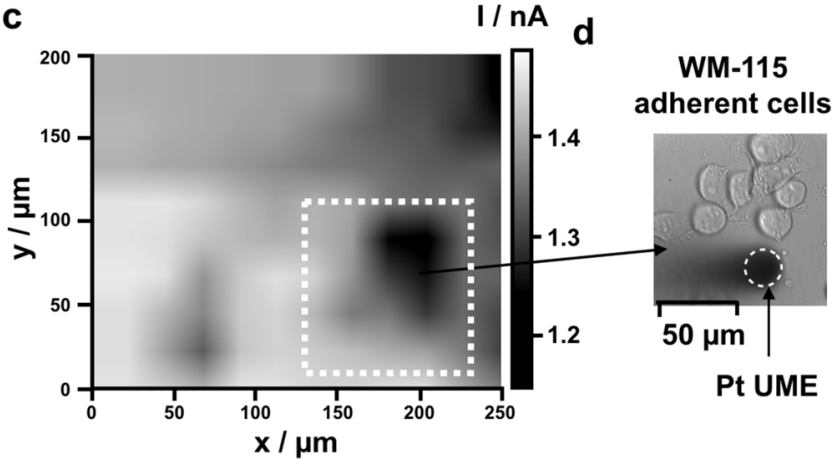

Figure 1. PI mask on glass surface employed to pattern different cell lines or the same cell line at different densities (a). Electrochemical signal (current) obtained during SECM line scan above fixed cells seeded at different concentrations (b). Electrochemical (c) and optical (d) image of a cell cluster. Experimental conditions: cells, WM-115; WE, Pt; QRE, Ag; CE, Pt. The scan rate and the working distance $d$ were equal to $5 \mu \mathrm{m} / \mathrm{s}$ and $25 \mu \mathrm{m}$, respectively. $\mathrm{FcCOOH}$ in experimental buffer ( 0.1 and $1 \mathrm{mM}$ for panels $\mathrm{b}$ and $\mathrm{c}$, respectively) was employed as the redox mediator.

medium $\left(\mathrm{C} 2=1.67 \times 10^{5}\right.$ cells $\left./ \mathrm{mL}\right)$ and 9 times diluted to obtain the lowest concentration $\left(\mathrm{C} 3=0.56 \times 10^{5}\right.$ cells $\left./ \mathrm{mL}\right)$. The initial cell concentration (C1) was determined by cell counting and extrapolation of a representative sample under an optical microscope.

Fixation and Permeabilization Protocol. Cells adherently grown on glass slides were fixed in a formaldehyde solution (at $4{ }^{\circ} \mathrm{C}, 15 \mathrm{~min}$ ). Membrane permeabilization was achieved by incubation of the fixed cells in the permeabilization buffer containing Triton X-100 for $20 \mathrm{~min}$ at room temperature (RT). After each process step, the sample was washed by immersion into PBS solution and incubation for $5 \mathrm{~min}$. The washing step was repeated three times. The intracellular TyR immunostaining was based on the fixation/permeabilization protocols combined with an immunohistochemistry (IHC) procedure (Supporting Information, section SI-I).

SECM Measurements. SECM experiments were performed by using a custom-built SECM setup running under SECMx software ${ }^{53}$ and combining a three-axis positioning system (Märzhäuser), an electronic tilt table (Zaber Technologies), and an Ivium potentiostat (CompactStat, Ivium Technologies). Measurements were carried out in a threeelectrode arrangement using a Pt ultramicroelectrode (UME) with Pt disk radius $r_{\mathrm{T}}=12.5 \mu \mathrm{m}$ and a surrounding glass sheath to metal disk ratio RG of 5 as working electrode (WE), a $\mathrm{Ag}$ wire as quasi-reference electrode (QRE), and a Pt wire as counter electrode (CE). All reported potentials are given with respect to the Ag-QRE. Collected data were treated and analyzed by using Origin and MIRA. ${ }^{54}$ 
a

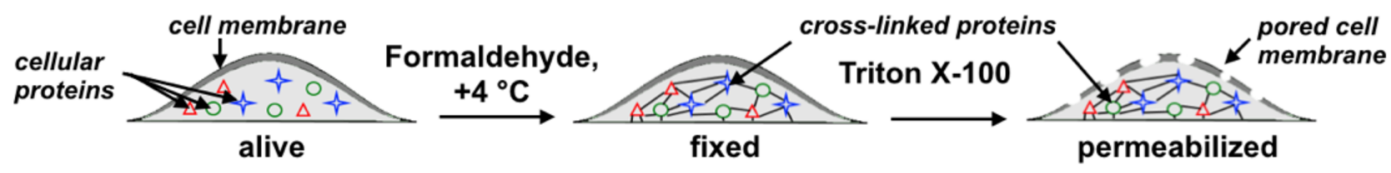

b

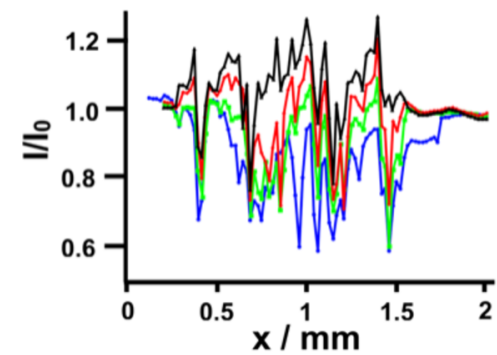

e

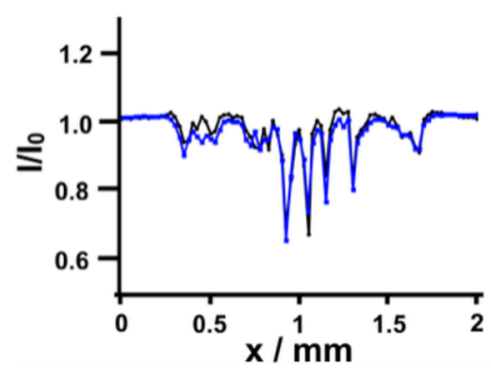

h

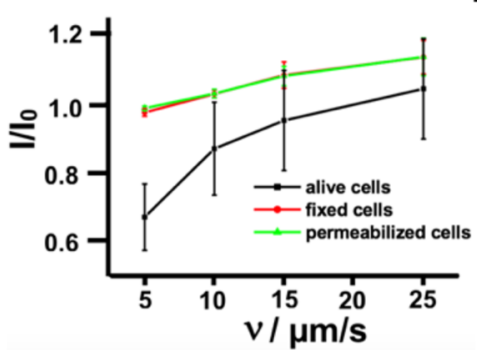

C
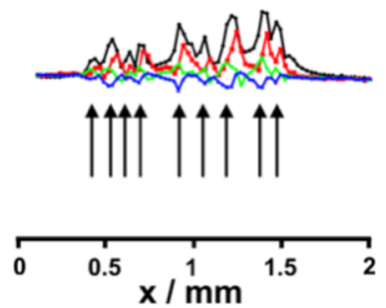

f

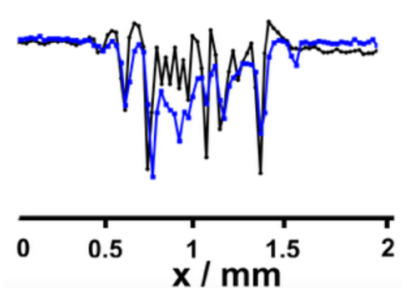

i

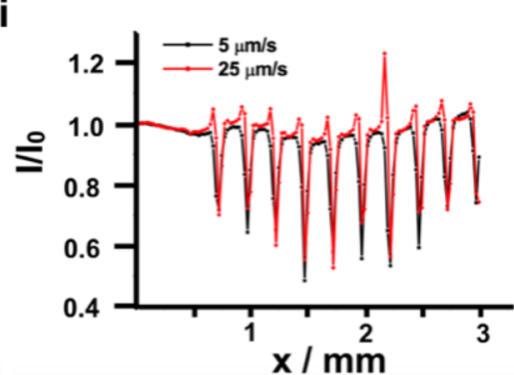

d

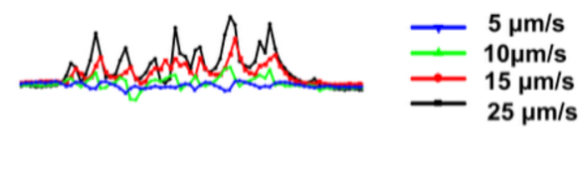

g

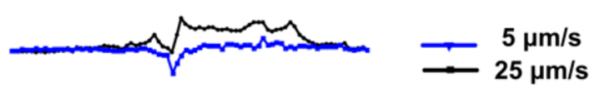

Figure 2. Schematic representation of alive, fixed, and permeabilized cell (a). Influence of the UME translation speed on the SECM response (normalized current) provided by alive ( $b$ and e), fixed ( $c$ and $\mathrm{f}$ ), and permeabilized ( $\mathrm{d}$ and $\mathrm{g}$ ) adherent WM-115 melanoma cells in the presence of noncharged $(\mathrm{FcMeOH}, \mathrm{b}-\mathrm{d})$ and charged $(\mathrm{FcCOOH}, \mathrm{e}-\mathrm{g})$ redox mediators. Dependence of the average value of normalized peak current on the UME translation rate obtained for alive, fixed, and permeabilized cells $(\mathrm{h})$. The error bars represent the standard deviation of the signal. Influence of the UME translation speed on the SECM response (normalized current) provided by the inkjet-printed sample, using FcMeOH as redox mediator (i). SECM response (normalized current) provided by BSA and TyR proteins spots adsorbed on PVDF membrane, when scanned with the translational speed $\nu$ equal to $25 \mu \mathrm{m} / \mathrm{s}$. (j). Experimental conditions: WE, Pt UME; QRE, Ag; CE, Pt. The working distance $d$ was equal to $25 \mu \mathrm{m}$.

Prior to all SECM line scans and imaging experiments, the sample surface was leveled using the tilt table and the height differences extracted from approach curves over insulating and cell-free regions in the presence of the corresponding redox mediator. Then, the UME was placed above the glass surface close to the cell area and positioned at a given working distance (i.e., $d=15$ or $25 \mu \mathrm{m}$ ) with respect to the bare substrate surface and the line scans were performed perpendicularly to the PI chambers direction with different translation rates (i.e., 5, 10, 15 , and $25 \mu \mathrm{m} / \mathrm{s}$ ). The effective translation speed is lower than the nominal one due to a required resting period of the UME at each measurement point of $0.1 \mathrm{~s}$ during signal acquisition and digitization by the potentiostat and the acceleration period for the UME to reach the maximum speed. Thus, the effective translation rates were equal to $4.7,8.9,13$, and $20 \mu \mathrm{m} / \mathrm{s}$, respectively. Electrochemical signals of the same cells in untreated, fixed, and permeabilized state were recorded subsequently. After the cell manipulation step and prior to the corresponding feedback-mode SECM experiment, the cell surface was gently washed with the redox mediator solution. $\mathrm{FcMeOH}$ and ferrocenecarboxylic acid $(\mathrm{FcCOOH})$ solutions (0.1 $\mathrm{mM}$ in SECM experimental buffer) were used as hydrophobic and hydrophilic redox mediators, respectively. Under the experimental conditions (i.e., $\mathrm{pH}=7.4$ ), $\mathrm{FcCOOH}$ $\left(\mathrm{p} K_{\mathrm{a}}=4.6\right)$ is present in the solution mainly as $\mathrm{FcCOO}^{-55}$

For the precise mapping of the melanoma biomarker $\mathrm{TyR}$ in fixed and permeabilized adherent melanoma cells, the immunostaining protocol was applied. 3,3',5,5'-Tetramethylbenzidine (TMB) was employed as a redox-active compound that gets oxidized to $\mathrm{TMB}_{\mathrm{ox}}$ at the immunolabeled TyR. The Pt UME was biased at the $\mathrm{TMB}_{\mathrm{ox}}$ reduction potential (i.e., $0.05 \mathrm{~V}$ ) and positioned at a defined $d$ and scanned over the cells in the substrate generation-tip collection (SG/TC) mode. To study the working distance effect on the obtained response, the UME was kept at a working distance equal to $15 \mu \mathrm{m}$ during the 
forward scan, while it was operated at $d=25 \mu \mathrm{m}$ during the reverse scan.

\section{RESULTS AND DISCUSSION}

Herein, SECM was employed for the investigation of melanoma cells cultured in a high-density population within the PI mask, which can provide complementary data from conditions closer to the ones observed on real tissue samples where neighboring cells can influence each other (Figure 1a). This cell patterning approach allows reducing the amount of cells to obtain high-density cell samples and facilitates the manipulation (e.g., transferring cells between the solutions) and patterning of different cell lines close to each other on the same substrate. However, this strategy is only suitable for cell lines that can be cultured under identical conditions (i.e., identical medium, temperature, etc.).

In order to investigate the influence of the cell density on the electrochemical feedback signal, SECM line scans were performed above WM-115 cells seeded at different dilutions within the same mask and fixed before the experiment, and with $\mathrm{FcCOOH}$ as redox mediator. Under these conditions, the detected signal (Figure 1b) should be influenced only by cell topography, i.e., the current above cells will be lower than above the glass surface due to the decrease of the working distance between the UME and the nonconductive substrate (for more detailed information see Supporting Information, section SI-III). As a result, a significant influence of the cell population on the magnitude of the obtained electrochemical signal was detected. An increase in the number of cells led to a higher decrease in the current recorded above the cells, illustrating the more pronounced blocking of the redox mediator diffusion toward the UME due to the presence of larger cells clusters (i.e., numerous cells grown in contact with each other forming a layer) and consequently higher surface coverage (i.e., close to $80 \%$ coverage; optical images of cell surfaces are given in Supporting Information, section SI-IV). Moreover, the difference between the lowest (C3) and the middle (C2) cell density case was much more pronounced in comparison with the middle and the highest $(\mathrm{C} 1)$ populated surfaces. The latter can be explained by (i) the UME size, similar to the size of the cell, resulting in low resolution of the experiments and (ii) the smaller difference in a blocking ability of clusters consisting of different cell numbers in comparison with a single cell (Figure 1b). Furthermore, even in case of the highest cell population, the cell-free areas within the dense cell layer led to current values similar to those obtained above the bare glass surface $\left(I / I_{0}=1\right)$. It is also important to note that the SECM investigation of a cell cluster under the given conditions does not allow the detection of the topographical issues of each cell within the cluster, as can be seen from the electrochemical image of the structure, consisting of seven WM-115 melanoma cells (Figure 1c; optical image of the cluster-Figure 1d). Thus, working with highly populated cell surfaces will lead to the averaging of the analytical signal, obtained from different cells in the cluster, presenting a general characteristic of the cell line.

Furthermore, investigation of cell topographical changes by AFM and SECM presented a nonsignificant increase in cells height after fixation (i.e., the maximum height of alive and fixed cells was $4-5$ and $6-7 \mu \mathrm{m}$, respectively), while permeabilization led to a slight decrease in comparison with fixed cells (i.e., the maximum height of permeabilized cells was 5-6 $\mu \mathrm{m}$ ). On the basis of the obtained results, it is worth noting that, since all the experiments were carried out in the constant height mode, the UME-cell surface distance is always $4-7 \mu \mathrm{m}$ smaller than the tip-substrate distance reported in this work, depending on the state of the cells. For more details, see Supporting Information, section SI-V.

In order to investigate any possible electrochemical activity of melanoma cells, SECM line scans were first performed above adherent WM-115 cells in alive, fixed, and permeabilized state (schematically represented in Figure 2a) using $\mathrm{FcMeOH}$ as redox mediator with different UME translational rates, i.e., 5, 10,15 , and $25 \mu \mathrm{m} / \mathrm{s}$ (Figure $2 \mathrm{~b}-\mathrm{d}$ and Figure S6, parts a and b). The current recorded at the UME when scanned above the insulating glass surface free of cells was used for normalization of the whole current profile as suggested elsewhere. ${ }^{56}$ This normalization allows taking into account the influence of UME translation speed on the SECM current over cell-free regions. As a result, when the translation speed was equal to $5 \mu \mathrm{m} / \mathrm{s}$ the current above alive cells was $20-40 \%$ lower than the one over the glass. However, an increase of the UME translation speed from 5 to $25 \mu \mathrm{m} / \mathrm{s}$ led to a significant change on the current profile recorded above the cells consisting of numerous current increases and decreases. Alternatively, scanning above fixed cells led to a simplified electrochemical signal, and a more defined current profile was recorded especially at high translation rates. When the translation speed was equal to $5 \mu \mathrm{m} / \mathrm{s}$ the current above fixed cells was lower than the one over the glass. However, when the UME translation rate reached $15 \mu \mathrm{m} / \mathrm{s}$ the recorded current above the cells presented values between $10 \%$ and $15 \%$ higher than above the glass slide (Figure 2c).

The SECM signals obtained with alive and fixed cells might be explained by the following points: (i) the current decrease is much stronger when cells are alive, while the height of the fixed cells is approximately $2 \mu \mathrm{m}$ larger, (ii) comparison of the results obtained at high scan rate (i.e., $15 \mu \mathrm{m} / \mathrm{s}$ and higher) presents current increase above both alive and fixed cells, which cannot be explained by enzymatic activity (i.e., since fixation eliminates the biological activity of the cells). Thus, other phenomena must play a role, such as an enhanced mass transport due to the fast translation rate and intrinsic electrochemical reactivity within the cell (vide infra). Additionally, the further permeabilization of the cells did not influence drastically the observed SECM signal (Figure 2d).

Interestingly, when a hydrophilic redox mediator was used (Figure $2 \mathrm{e}-\mathrm{g}$ ), both alive and fixed cells provided a significant current decrease over the cell culture, which was only slightly influenced by the UME translation speed (Figure 2, parts e and f). The latter might be explained by the difficulty of the redox mediator to access the intracellular space and the absence of any cellular activity. Additionally, after scanning permeabilized cells at different translation rates, a similar behavior to the one presented in the case of hydrophobic redox mediator was observed (Figure 2g). By comparing the results obtained for hydrophobic and hydrophilic redox mediators, it can be suggested that, when the cells are permeabilized and scanned at high translation rates, a regeneration of redox mediator can still be observed. An explanation for this effect is discussed later in this work. Finally, similar to Figure 1c, a clear presence of cell-free areas in the cell monolayer can be observed so that few clusters can be distinguished (i.e., nine clusters, black arrows, Figure 2c).

To further compare the influence of the UME translation speed on the SECM response of alive, fixed, and permeabilized cells grown in clusters using a hydrophobic redox mediator, Figure $2 b-d$ were converted into the normalized peak 
current-translational speed coordinates (Figure $2 \mathrm{~h}$ ). The positions of the negative current peaks, which appeared when scanning above fixed cells with the translation speed equal to 5 $\mu \mathrm{m} / \mathrm{s}$, were chosen as the most representative cell cluster points (Figure 2c, black arrows), and these $x$-coordinates were used to construct the $I / I_{0}-\nu$ graph, as reported by Kuss et al. ${ }^{56}$ As a result, averaging the current value for alive cells (i.e., nine cell clusters) leads to significant error bars in the cell characterization (Figure $2 \mathrm{~h}$ ) and illustrates the difficulties associated with SECM studies of alive cell cultured at high density. The variation of the signal can be due to the presence of cells at different growth stages and due to the cell-to-cell variation of intracellular biological and electrochemical activity. At the same time, cell fixation and permeabilization revealed identical dependence of the normalized current as a function of the UME translational rate in case of hydrophobic redox mediators (Figure 2h).

In order to better understand the nature of the current increase recorded over alive, fixed, and permeabilized cells at high UME translation rates, a few hypotheses were studied, namely, an increase on the mass transport due to an enhanced convection during fast scanning over nonplanar samples and the presence of an intracellular reactivity or the release of redox species by cells. With the aim to determine the contribution of an enhanced convection to the recorded signal, an array of dielectric spots was inkjet-printed on a glass substrate to mimic the topography of the adherent cancer cells. The prepared sample contained several spots, topographically similar to an adherent cancer cell ( $30 \mu \mathrm{m}$ diameter and approximately $6 \mu \mathrm{m}$ height) positioned $250 \mu \mathrm{m}$ from each other, completely impermeable and inert to the redox mediators. As a result, a clear decrease of the recorded current at the UME occurs when it was scanned over the dielectric spots for both 5 and $25 \mu \mathrm{m} / \mathrm{s}$ translation speeds. However, when scanning at $25 \mu \mathrm{m} / \mathrm{s}$ translation rate a slight current increase is also observed just before the drastic current decrease when the probe starts to scan the dielectric spot, which is similar to what was observed with alive and fixed cells when $\mathrm{FcCOOH}$ was used as a redox mediator (optical images and additional experimental results can be found in Supporting Information, section SI-VII). The latter results suggest that the forced convection introduced by the fast UME movement above the nonplanar substrate can be a reason for the differences in the slow and fast scanning rates (i.e., 5 and $25 \mu \mathrm{m} / \mathrm{s}$ ) in case of the hydrophilic redox mediator (Figure 2, parts e and f). However, it does not explain the observed response when using the hydrophobic redox mediator.

Another important origin of the current increase at high translation rates is the intrinsic biological activity of the studied cells, which could be able to release redox-active species into the extracellular space as a response to external effectors (e.g., presence of redox mediator) or could recycle the redox species that are able to travel into the intracellular space. In the case of fixed and permeabilized cells, where no biological activity should be present, the current increase can be related to the presence of various electrochemically active species (e.g., amino acids and heme groups present in proteins). In order to evaluate the possible electrochemical activity of proteins, two model compounds, i.e., bovine serum albumin (BSA) and TyR, were adsorbed on a poly(vinylidene fluoride) (PVDF) membrane (no membrane height change was observed during spotting, Supporting Information, section SI-VIII) and investigated under identical conditions as for the cell experiments. Both proteins contain electrochemically active amino acids (e.g., arginine, lysine, and cysteine) and TyR contains additionally an active copper center. As a result, a clear current increase was observed when scanning above both proteins in feedback mode using $\mathrm{FcMeOH}$ and $\mathrm{FcCOOH}$ as redox mediators, especially at the edges of the protein spots due to the well-known "coffee ring" effect (Figure 2j). These results suggest that adsorbed proteins could have an electrochemical activity $^{57,58}$ that leads to the chemical reduction and, thus, regeneration of the redox mediator previously oxidized at the UME. Therefore, the increase of the current in case of fixed cells and hydrophobic redox mediator can be (at least partially) due to the impact of the intracellular redox-active proteins.

As reported elsewhere, employing SECM with $\mathrm{FcMeOH}$ as redox mediator allowed the distinction of MCF10A cells expressing active Ha-Ras Val12 mutant compared to normal MCF10A, apparently by measuring oxidized/reduced glutathione balance in human breast epithelial cells. ${ }^{59}$ Moreover, it was shown that metastatic and nonmetastatic breast cancer cells can be differentiated based on the SECM monitoring of the redox environment. ${ }^{60}$ Therefore, in order to investigate whether any difference in electrochemical behavior of different stage melanoma cells can be observed, three melanoma cell lines (i.e., Sbcl2, WM-115, and WM-239) corresponding to the radial growth (RGP), vertical growth (VGP), and metastatic phases of melanoma, respectively, were cultured on the same glass slide within different PI mask chambers. SECM line scans above alive, fixed, and permeabilized cells using hydrophobic redox mediator were performed. As a result, all three melanoma cell lines were hardly distinguishable (Figure $3 \mathrm{a}$, only $10 \mu \mathrm{m} / \mathrm{s}$ scan rate is presented as an example) based on their accessible redox-active content. Despite the inability to distinguish different cell lines directly, the similarity in the analytical signal, provided by different cell lines in permeabilized state, can be beneficial for the electrochemical detection of the immunocomplexes, in the case when the immunostaining approach was employed. In this situation, one can expect either no or equal interference of the intracellular species on the resulting current, which could be suitable for the detection of the intracellular biomarkers, such as $\mathrm{TyR}^{61}$ by SECM. Previously, TyR distribution was successfully investigated by SECM in combination with an immunostaining approach, within the fixed tissues. ${ }^{62}$ However, when working with adherent cells, the direct immunostaining of this biomarker appeared to be impossible since it cannot be reached by antibodies due to the inability of large proteins to penetrate across the cell membrane. In this case, the fixation/ permeabilization approach can be indeed beneficial.

In order to evaluate the influence of cell topography and cell reactivity on the detected electrochemical signal, fixed/ permeabilized cells that have not been immunostained were investigated by using a UME located at a probe-substrate distance equal to $15 \mu \mathrm{m}$ in the presence of TMB. As a result, no significant influence of these factors was observed, which suggests that, under the experimental conditions, SECM imaging of the immunostained intracellular TyR can be performed without any external interference. Furthermore, the evaluation of the nonspecific binding of antimouse AbsHRP on fixed and permeabilized cells presented an insignificant increase of the current (i.e., 5-10\%) indicating that the signal coming from nonspecific binding is negligible in comparison with the detected analytical current when specific TyR labeling was performed. 
a

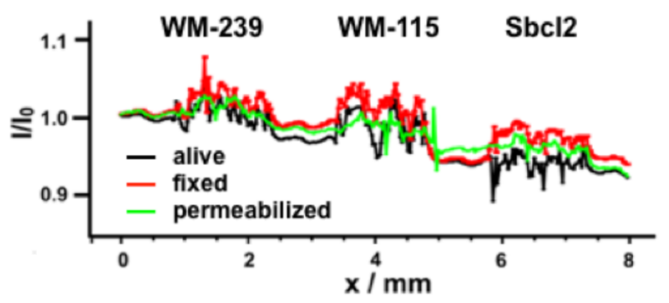

b

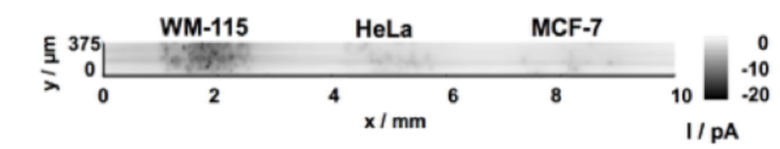

C

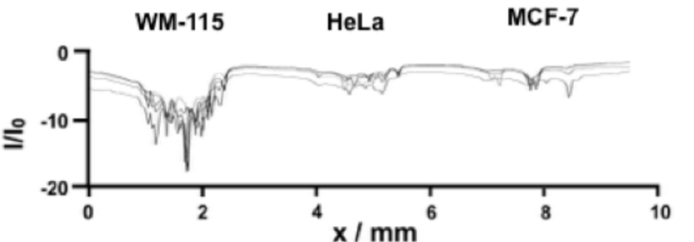

d

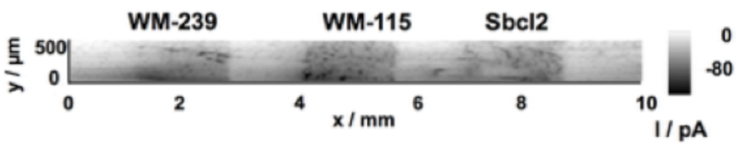

e

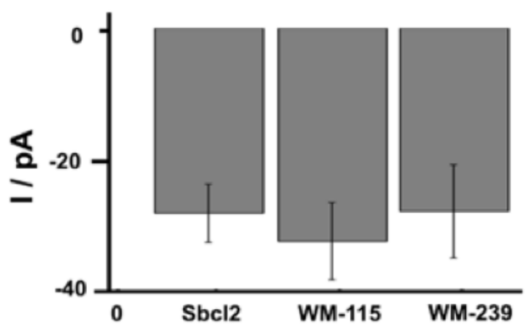

Figure 3. Electrochemical results obtained for three different cell lines grown within the same PI mask and analyzed in different states by SECM in the feedback mode, using $0.1 \mathrm{mM} \mathrm{FcMeOH}$ as a redox mediator (a). Investigation of TyR expression inside adherent cells by SECM using an immunoassay strategy $(b-d)$. The studied sample consisting of WM-115, HeLa, and MCF-7 (b and c), and three different melanoma cell lines, namely, WM-239, WM-115, and Sbcl2 (d and e), were studied by SECM (b). Average current with standard deviation obtained for different melanotic cell lines (e). Experimental conditions: WE, Pt UME; QRE, Ag; CE, Pt. The working distance $d$ was equal to 15 and $25 \mu \mathrm{m}$, and the UME translational speed was equal to $10 \mu \mathrm{m} / \mathrm{s}$ (a) and $25 \mu \mathrm{m} / \mathrm{s}$ (b-e), respectively.

To further assess the specificity of the immunostaining protocol employed, the suggested strategy was applied for the staining of HeLa and MCF-7 cell lines, which do not contain $\mathrm{TyR}^{6,63,64}$ in contrast to human melanoma WM-115 cell line. ${ }^{65,66}$ The SECM image of the TyR expression in WM115, HeLa, and MCF-7 adherent cells grown at the same cell density (i.e., $\mathrm{C} 1$ ), as well as the representative line scans, are presented in Figure 3, parts $\mathrm{b}$ and $\mathrm{c}$. The results of the experiment showed a good agreement with the data reported in the literature, i.e., the value of the current provided by HeLa and MCF-7 cells was negligible in comparison with the analytical signal recorded above WM-115 cells. Additionally, a significant heterogeneity on the current recorded over the HeLa and MCF-7 cell lines shows the nonspecific nature of the signal obtained for the nonmelanocytic cells. Thus, the developed approach for the intracellular TyR immunostaining with SECM readout was further extended for the investigation of this biomarker expression in different melanoma cell lines.
The expression of TyR was evaluated in three different melanoma cell lines corresponding to different cancer progression stages, namely, Sbcl2, WM-115, and WM-239. The results of the TyR immunostaining mapped by SECM are presented in Figure 3, parts d and e. As expected, all the melanotic cell lines showed a significant expression of TyR. In order to further compare the different cell lines, an average current corresponding to every cell chamber was recalculated, as discussed in the Supporting Information, section SI-X. As a result, the highest TyR expression was detected in the WM-115 cell line (Figure 3e), which can be assigned to the vertical growth phase based on the Clark model ${ }^{67}$ and stage II of melanoma according to the American Joint Commission on Cancer (AJCC), presenting good correlation with previously published data for skin cancer tissues. ${ }^{62}$ The cells derived from radial growth phase RGP and metastatic melanomas presented lower amounts of TyR.

It is also worth noticing that $\mathrm{TMB}_{\text {ox }}$ can be accumulated inside cells, and therefore, the signals detected above cells depend on the incubation time. Thus, the difference in the current in Figure 3, parts b and d, for the same cell line (i.e., WM-115) can be explained by different times spent for the sample leveling as well as for the surface imaging. The latter highlights the need to scan all the cell lines under the same experimental conditions and also validates their differentiation based on the different TyR expression level.

\section{CONCLUSIONS}

The potential of SECM imaging of fixed and permeabilized cells was evaluated. For this purpose, cells were cultured within specially designed disposable PI masks and studied by SECM in alive, fixed, and permeabilized state. The influence of different parameters, e.g., the redox mediator type (i.e., hydrophobic or hydrophilic), the probe translation rate, and the cell population density, on the SECM signal was investigated. For instance, current increases can be observed over the scanned cells when $\mathrm{FcMeOH}$ is used and the UME is translated with a speed equal or higher than $10 \mu \mathrm{m} / \mathrm{s}$. As presented in this work, this phenomenon cannot be explained only by forced convection due to the cell topography and fast translation rates, but can also be a result of the presence of intracellular species with significant electrochemical activity (e.g., proteins).

Additionally, SECM line scans above alive melanoma cells with $\mathrm{FcMeOH}$ as a redox mediator presented a significant signal variation within the same cell line, which posed inevitable difficulties in the interpretation of the obtained results. In contrast, the current profile recorded above fixed and permeabilized cells is highly reproducible. Unfortunately, the direct assay of the fixed and permeabilized melanoma cells did not present any significant differences between different cell lines. Nevertheless, the fixation/permeabilization approach opens the intracellular space for performing immunostaining of the intracellular components. As a proof of concept, SECM was implemented as a tool to monitor the presence of $\mathrm{TyR}$ in melanoma adherent cells by electrochemical readout of an immunoassay strategy. The protocol was optimized and successfully implemented for TyR imaging within different melanotic and nonmelanotic cell lines. To the best of our knowledge, this work pioneers the SECM imaging of specifically targeted intracellular biomarkers within adherent cells using cell fixation and immunoassay protocols. 


\section{ASSOCIATED CONTENT}

\section{S Supporting Information}

The Supporting Information is available free of charge on the ACS Publications website at DOI: 10.1021/acs.analchem.6b02379.

Chemicals and buffers, preparation of the PI masks, SECM of alive, fixed, and permeabilized cells, influence of cell density on SECM signal, optical and AFM characterization of cell topography, IJP cell-like sample preparation and its investigation by SECM, immobilization of proteins on PVDF membrane and their investigation by SECM, influence of cell topography, nonspecific binding and working distance on the TyR detection by SECM/immunoassay protocol as well as data extraction from the SECM image of intracellular TyR (PDF)

\section{AUTHOR INFORMATION}

\section{Corresponding Authors}

*E-mail: alexandra.bondarenko@epfl.ch. Phone: +41 2169 33144. Fax: +41216933667.

*E-mail: horst.pick@epfl.ch. Phone: +41 2169 33132. Fax: +41 216933667.

\section{Author Contributions}

The manuscript was written through contributions of all authors. All authors have given approval to the final version of the manuscript.

Notes

The authors declare no competing financial interest.

\section{ACKNOWLEDGMENTS}

The authors are thankful to the SNSF from Switzerland and the UEFISCDI from Romania for their support through the joint project no. IZERZO_142236/1. T.-E.L. gratefully acknowledges the Taiwan government for "The 2013 MOE Technologies Incubation Scholarship".

\section{REFERENCES}

(1) Bard, A. J.; Denuault, G.; Lee, C.; Mandler, D.; Wipf, D. O. Acc. Chem. Res. 1990, 23, 357-363.

(2) Bard, A. J.; Fan, F. F.; Kwak, J.; Lev, O. Anal. Chem. 1989, 61, 132-138.

(3) Mirkin, M. V.; Nogala, W.; Velmurugan, J.; Wang, Y. Phys. Chem. Chem. Phys. 2011, 13, 21196-21212.

(4) Bard, A. J.; Mirkin, M. V. Scanning Electrochemical Microscopy, 2nd ed.; CRC Press: Boca Raton, FL, 2012.

(5) Bard, A. J.; Li, X.; Zhan, W. Biosens. Bioelectron. 2006, 22, 461472.

(6) Schulte, A.; Nebel, M.; Schuhmann, W. Annu. Rev. Anal. Chem. 2010, 3, 299-318.

(7) Bergner, S.; Vatsyayan, P.; Matysik, F.-M. Anal. Chim. Acta 2013, $775,1-13$.

(8) Zhang, Y.; Ma, J.; Zhang, Y.; Jiang, H.; Wang, X. Nanosci. Nanotechnol. Lett. 2013, 5, 182-185.

(9) Sun, P.; Laforge, F. O.; Abeyweera, T. P.; Rotenberg, S. A.; Carpino, J.; Mirkin, M. V. Proc. Natl. Acad. Sci. U. S. A. 2008, 105, $443-448$.

(10) Kaya, T.; Torisawa, Y.; Oyamatsu, D.; Nishizawa, M.; Matsue, T. Biosens. Bioelectron. 2003, 18, 1379-1383.

(11) Torisawa, Y.-S.; Kaya, T.; Takii, Y.; Oyamatsu, D.; Nishizawa, M.; Matsue, T. Anal. Chem. 2003, 75, 2154-2158.

(12) Bergner, S.; Wegener, J.; Matysik, F.-M. Anal. Methods 2012, 4, $623-629$.
(13) Nishizawa, M.; Takoh, K.; Matsue, T. Langmuir 2002, 18, 3645-3649.

(14) Kuss, S.; Polcari, D.; Geissler, M.; Brassard, D.; Mauzeroll, J. Proc. Natl. Acad. Sci. U. S. A. 2013, 110, 9249-9254.

(15) Sridhar, A.; De Boer, H. L.; Van Den Berg, A.; Le Gac, S. PLoS One 2014, 9, e93618.

(16) Shiku, H.; Shiraishi, T.; Ohya, H.; Matsue, T.; Abe, H.; Hoshi, H.; Kobayashi, M. Anal. Chem. 2001, 73, 3751-3758.

(17) Takahashi, R.; Zhou, Y.; Horiguchi, Y.; Shiku, H.; Sonoda, H.; Itabashi, N.; Yamamoto, J.; Saito, T.; Matsue, T.; Hisada, A. J. Biosci. Bioeng. 2014, 117, 113-121.

(18) Shiku, H.; Shiraishi, T.; Aoyagi, S.; Utsumi, Y.; Matsudaira, M.; Abe, H.; Hoshi, H.; Kasai, S.; Ohya, H.; Matsue, T. Anal. Chim. Acta 2004, 522, 51-58.

(19) Obregon, R.; Horiguchi, Y.; Arai, T.; Abe, S.; Zhou, Y.; Takahashi, R.; Hisada, A.; Ino, K.; Shiku, H.; Matsue, T. Talanta 2012, 94, 30-35.

(20) Shiku, H.; Torisawa, Y.; Takagi, A.; Aoyagi, S.; Abe, H.; Hoshi, H.; Yasukawa, T.; Matsue, T. Sens. Actuators, B 2005, 108, 597-602.

(21) Nebel, M.; Grützke, S.; Diab, N.; Schulte, A.; Schuhmann, W. Angew. Chem., Int. Ed. 2013, 52, 6335-6338.

(22) Yasukawa, T.; Kondo, Y.; Uchida, I.; Matsue, T. Chem. Lett. 1998, 27, 767-768.

(23) Salamifar, S. E.; Lai, R. Y. Anal. Chem. 2013, 85, 9417-21.

(24) Zhang, M. M. N.; Long, Y.-T.; Ding, Z. J. Inorg. Biochem. 2012, $108,115-122$.

(25) Zhao, X.; Diakowski, P. M.; Ding, Z. Anal. Chem. 2010, 82, 8371-8373.

(26) Isik, S.; Schuhmann, W. Angew. Chem., Int. Ed. 2006, 45, 74517454.

(27) Pitta Bauermann, L.; Schuhmann, W.; Schulte, A. Phys. Chem. Chem. Phys. 2004, 6, 4003-4008.

(28) Yasukawa, T.; Uchida, I.; Matsue, T. Biochim. Biophys. Acta, Biomembr. 1998, 1369, 152-158.

(29) Zhan, D.; Li, X.; Nepomnyashchii, A. B.; Alpuche-Aviles, M. A.; Fan, F. R. F.; Bard, A. J. J. Electroanal. Chem. 2013, 688, 61-68.

(30) Li, X.; Bard, A. J. J. Electroanal. Chem. 2009, 628, 35-42.

(31) Kuss, S.; Cornut, R.; Beaulieu, I.; Mezour, M. A.; Annabi, B.; Mauzeroll, J. Bioelectrochemistry 2011, 82, 29-37.

(32) Mauzeroll, J.; Bard, A. J. Proc. Natl. Acad. Sci. U. S. A. 2004, 101, $7862-7867$

(33) Koley, D.; Bard, A. J. Proc. Natl. Acad. Sci. U. S. A. 2012, 109, $11522-11527$.

(34) Matsumae, Y.; Takahashi, Y.; Ino, K.; Shiku, H.; Matsue, T. Anal. Chim. Acta 2014, 842, 20-26.

(35) Rotenberg, S. A.; Mirkin, M. V. J. Mammary Gland Biol. Neoplasia 2004, 9, 375-382.

(36) Amemiya, S.; Guo, J.; Xiong, H.; Gross, D. A. Anal. Bioanal. Chem. 2006, 386, 458-471.

(37) Yasukawa, T.; Kaya, T.; Matsue, T. Electroanalysis 2000, 12, 653-659.

(38) Li, M. S. M.; Filice, F. P.; Ding, Z. J. Electroanal. Chem. 2016, $779,176-186$.

(39) Gao, N.; Wang, X.; Li, L.; Zhang, X.; Jin, W. Analyst 2007, 132, $1139-1146$

(40) Filice, F. P.; Li, M. S. M.; Henderson, J. D.; Ding, Z. Anal. Chim. Acta 2016, 908, 85-94.

(41) Li, M. S. M.; Filice, F. P.; Henderson, J. D.; Ding, Z. J. Phys. Chem. C 2016, 120, 6094-6103.

(42) Henderson, J. D.; Filice, F. P.; Li, M. S. M.; Ding, Z. J. Inorg. Biochem. 2016, 158, 92-98.

(43) Li, M. S. M.; Filice, F. P.; Ding, Z. J. Inorg. Biochem. 2014, 136, $177-183$.

(44) Xue, Y.; Ding, L.; Lei, J.; Yan, F.; Ju, H. Anal. Chem. 2010, 82, $7112-7118$.

(45) Takahashi, Y.; Miyamoto, T.; Shiku, H.; Ino, K.; Yasukawa, T.; Asano, R.; Kumagai, I.; Matsue, T. Phys. Chem. Chem. Phys. 2011, 13, 16569-16573. 
(46) Braet, F.; Rotsch, C.; Wisse, E.; Radmacher, M. Appl. Phys. A: Mater. Sci. Process. 1998, 66, S575-S578.

(47) Morkvènaitè-Vilkončienè, I.; Ramanavičienė, A.; Ramanavičius, A. Medicina (Kaunas) 2013, 49, 155-164.

(48) Yamane, Y.; Shiga, H.; Haga, H.; Kawabata, K.; Abe, K.; Ito, E. J. Electron Microsc. 2000, 49, 463-471.

(49) Korchev, Y. E.; Gorelik, J.; Lab, M. J.; Sviderskaya, E. V.; Johnston, C. L.; Coombes, C. R.; Vodyanoy, I.; Edwards, C. R. Biophys. J. 2000, 78, 451-457.

(50) Novak, P.; Li, C.; Shevchuk, A. I.; Stepanyan, R.; Caldwell, M.; Hughes, S.; Smart, T. G.; Gorelik, J.; Ostanin, V. P.; Lab, M. J.; Moss, G. W. J.; Frolenkov, G. I.; Klenerman, D.; Korchev, Y. E. Nat. Methods 2009, 6, 279-281.

(51) Watkins, S. Curr. Protoc. Cytom. 2009, 48, 12.16.1-12.16.10.

(52) Orchard, G. E. Histochem. J. 2000, 32, 475-481.

(53) Nunes Kirchner, C.; Hallmeier, K. H.; Szargan, R.; Raschke, T.; Radehaus, C.; Wittstock, G. Electroanalysis 2007, 19, 1023-1031.

(54) Wittstock, G.; Asmus, T.; Wilhelm, T. Fresenius' J. Anal. Chem. 2000, 367, 346-351.

(55) Yamada, H.; Matsue, T.; Uchida, I. Biochem. Biophys. Res. Commun. 1991, 180, 1330-1334.

(56) Kuss, S.; Kuss, C.; Trinh, D.; Schougaard, S. B.; Mauzeroll, J. Electrochim. Acta 2013, 110, 42-48.

(57) Permentier, H. P.; Bruins, A. P. J. Am. Soc. Mass Spectrom. 2004, 15, 1707-1716.

(58) Roeser, J.; Permentier, H. P.; Bruins, A. P.; Bischoff, R. Anal. Chem. 2010, 82, 7556-7565.

(59) Rapino, S.; Marcu, R.; Bigi, A.; Soldà, A.; Marcaccio, M.; Paolucci, F.; Pelicci, P. G.; Giorgio, M. Electrochim. Acta 2015, 179, $65-73$.

(60) Liu, B.; Rotenberg, S. A.; Mirkin, M. V. Proc. Natl. Acad. Sci. U. S. A. 2000, 97, 9855-9860.

(61) Halaban, R.; Cheng, E.; Zhang, Y.; Moellmann, G.; Hanlon, D.; Michalak, M.; Setaluri, V.; Hebert, D. N. Proc. Natl. Acad. Sci. U. S. A. 1997, 94, 6210-6215.

(62) Lin, T.-E.; Bondarenko, A.; Lesch, A.; Pick, H.; Cortés-Salazar, F.; Girault, H. H. Angew. Chem., Int. Ed. 2016, 55, 3813-3816.

(63) Guo, J.; Wen, D. R.; Huang, R. R.; Paul, E.; Wünsch, P.; Itakura, E.; Cochran, A. J. Exp. Mol. Pathol. 2003, 74, 140-147.

(64) McEwan, M.; Parsons, P. G.; Moss, D. J. J. Invest. Dermatol. 1988, 90, 515-519.

(65) Al-Ghoul, M.; Bruck, T. B.; Lauer-Fields, J. L.; Asirvatham, V. S.; Zapata, C.; Kerr, R. G.; Fields, G. B. J. Proteome Res. 2008, 7, 41074118.

(66) Milani, V.; Frankenberger, B.; Heinz, O.; Brandl, A.; Ruhland, S.; Issels, R. D.; Noessner, E. Int. Immunol. 2005, 17, 257-268.

(67) Miller, A. J.; Mihm, M. C. N. Engl. J. Med. 2006, 355, 51-65. 